\title{
The West That is Wyoming: The Hebard Historic Map Collection, University of Wyoming Libraries
}

\author{
Tami Morse \\ Catalog Librarian \\ University of Wyoming Libraries \\ tmorsemc@uwyo.edu
}

Head, Emmett D. Chisum Special Collections
University of Wyoming Libraries
thert@uwyo.edu
IN 2009, the University of Wyoming completed a major expansion and renovation of William R. Coe Library, the main library on campus. Among the project's many improvements was the creation of a dedicated space to house and provide access to rare, valuable, and historically significant materials. The Libraries' Grace Raymond Hebard Collection, consisting predominately of published materials about Wyoming and considered the most comprehensive of its kind, had been housed with the University Archives in the American Heritage Center since the mid 1990s. This collection was returned to Coe Library in 2010, where it was united with other special materials to create a new department: the Emmett D. Chisum Special Collections. One of the collections reunited in the new department at this time was the Hebard Historic Map Collection.

\section{THE HISTORY AND DEVELOPMENT OF THE HEBARD HISTORIC MAP COLLECTION}

The Collection is nAmed for Grace Raymond Hebard, who came to Wyoming in 1882. She worked as a draftsman for the United States Surveyor General's Office in Cheyenne, becoming the Assistant State Engineer in 1886. Her work as a draftsman involved creating maps from surveyors' notes. (Mackey 2005). In 1891, she was appointed a trustee of the University of Wyoming, five years after the University was established by the Wyoming Legislature. In 1893, she became Assistant Professor of Political Economics and, in 1894, the University's Librarian. She used her skills as a draftsman and cartographer throughout her career, tracing and mapping historic trails in Wyoming, drawing maps to accompany her books, and creating the Map of the History and Romance of Wyoming in 1928. Her collection of books and maps became the kernel of the Grace Raymond Hebard Collection on Wyoming history and culture and the Hebard Historic Map Collection.

During the time Hebard served as Librarian, the General Library contained books of general interest with more specialized materials residing in separate libraries administered by the departments. In annual reports to the University President, Hebard writes about both the General Library and the Political Economy department, which had its own library. In 1919, she compares the budgets for the General Library and the departmental libraries, noting that some departmental libraries receive the same funding as the General Library. The only mention of maps in these reports are line items in the Political Economy Department budget, for "maps, supplies, and incidentals" (Grace Raymond Hebard to Aven Nelson, Grace Raymond Hebard papers, Box 4, Folder 1).

Almost from the beginning, the division between the General Library and the departmental libraries generated discussion. In the minutes from a Library Committee meeting dated August 9, 1894, the committee resolved to have all technical books cataloged as part of the University Library before being turned over to the departments whose professors purchased them. In 1923, the committee voted to consolidate all departmental libraries into the main library but the merger apparently did not take place until the 1960s. As of May 1, 1950-before the consolidation-the Main Library contained 157 maps; that number probably grew substantially after the consolidation as maps housed in the departmental libraries became part of the main collection. 


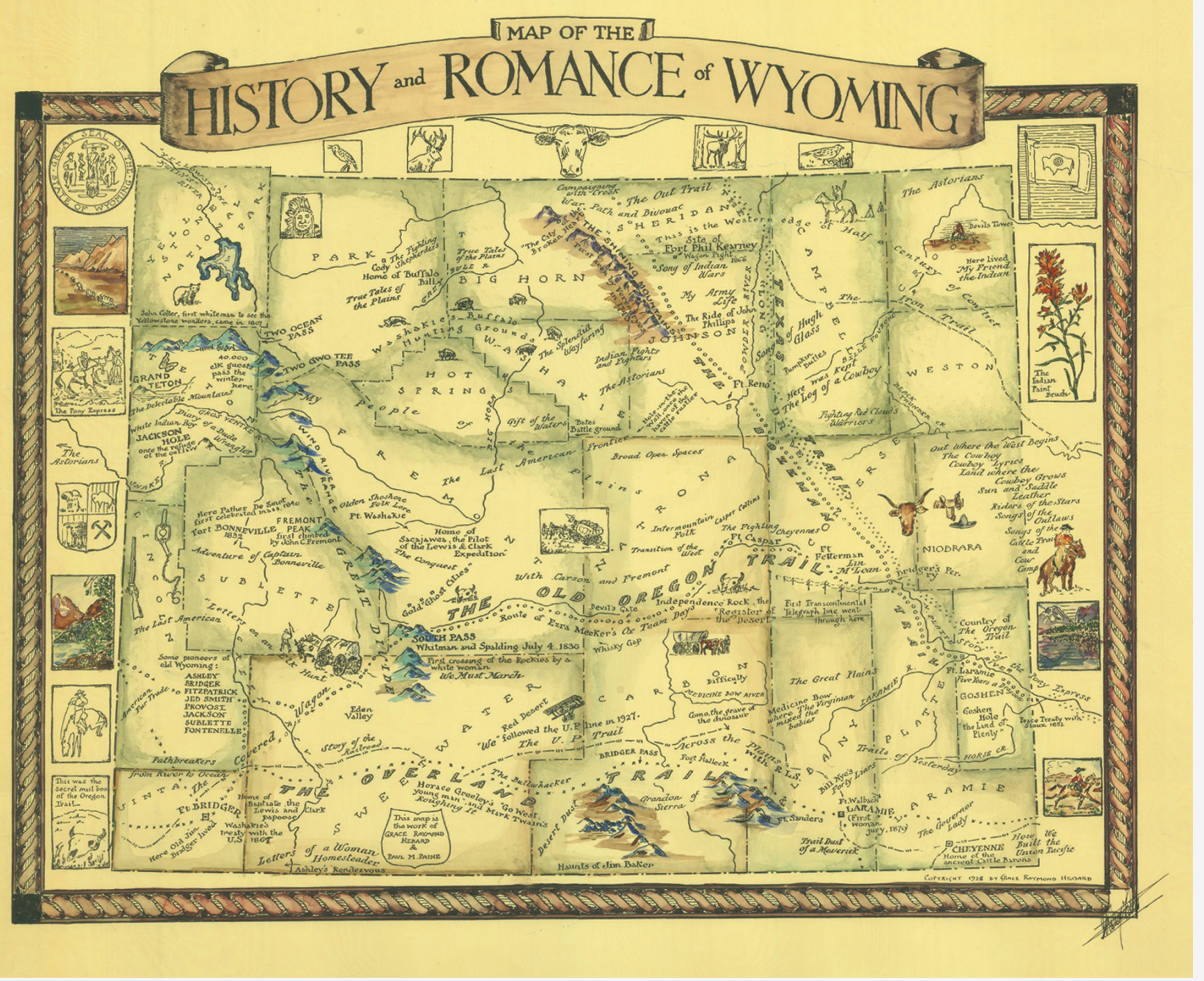

Figure 1: Map of the History and Romance of Wyoming. 1928. Grace Raymond Hebard. Signed by Grace Raymond Hebard.

Library newsletters and annual reports through the 1980s contain lists of materials purchased but maps are rarely mentioned. This makes them seem an unimportant part of the collection but, in 1982, the Libraries hired their first Map Librarian, James Walsh. Also in 1982, a room was set aside to house historic maps and atlases within Coe Library, but the bulk of the map collection consisted of depository documents from the United States Geological Survey, the Defense Mapping Agency, the CIA, and other federal government agencies.

In an email message dated February 20, 2013, Walsh discussed how he worked to build the map collection during his tenure, adding collections of Wyoming city and highway maps and purchasing historic maps of the state. The first accurate count of maps in the main library collection was completed in 1983 and found 93,667 maps (Walsh 1983). The 100,000th map was added in 1984 (Walsh 1984). Walsh was named Geology and Maps Librarian in 1985, giving him responsibility for the map collections in both the main library and the Geology branch (the only departmental library not closed after the consolidation.) The Geology Library held 25,000 maps as of June 1986 (Walsh 1987).

The number of maps in the collections increased steadily over time, but maps were still not considered "full-fledged" materials. According to Janet Woods, who worked in the Geology Library beginning in 1981, maps were treated as tools at that time: they were checked out to researchers to 
use as they saw fit. Topographic maps were disposable and replaced when hard wear made them unusable. Maps were acquired from the Wyoming State Geological Survey and the Federal Depository Library Program. Most depository maps were kept in the main library; topo maps and depository geologic maps were in the Geology Library. When maps were purchased, it was primarily for classroom use rather than collection building or historic preservation. Still, the first materials that UW Libraries paid to have preserved were a set of atlases, the Geologic Atlases of Wyoming (Janet Woods, personal communication). Maps may have been tools but they were tools worth saving.

In the 1990s, the Geology Library was renovated and the bulk of the map collection was moved to the Barlow and Haun Map Room. The historic collection remained at Coe Library and became the core of the Hebard Historic Map Collection. In the late 1990s, the decision was made to catalog the Wyoming maps in the historic map collection and place them at the American Heritage Center, an archival institute within the University of Wyoming, with the Hebard Collection, where archives staff could provide access and where the materials were stored in an appropriate environment. Only the 7.5' topographic maps remained in the Historic Map Room.

When the Coe Library construction was completed and the new special collections area was ready, both the Hebard Collection and the historic maps were returned. The new space provides a reading room and secured stacks area. The stacks consist primarily of compact shelving, with a section of map cases for flat maps, and wall-mounted racks for rolled wall maps. A special set of drawers are fitted into one of the compact shelving ranges, to provide separate storage for small maps. This ensures these maps, no less important for their size, are better preserved and more easily accessible than if they were hidden among their larger siblings.

\section{SOME HIGHLIGHTS FROM THE COLLECTION}

The collecting focus of the Chisum Special Collections is the history and culture of Wyoming and the Rocky Mountain West, with one emphasis on Yellowstone and Grand Teton National Parks and other western National Parks. The Historic Map Collection supports this focus with maps depicting Wyoming and the West from its exploration to the present day.
The collection naturally contains several of Grace Raymond Hebard's published maps including her best-known one, The Map of the History and Romance of Wyoming (Figure 1). Most she created to accompany her books on Wyoming and Western history. For example, her Map of the Oregon Trail and Overland Stage Routes (Figure 2), created with E. A. Brininstool, was published as part of their 1922 book

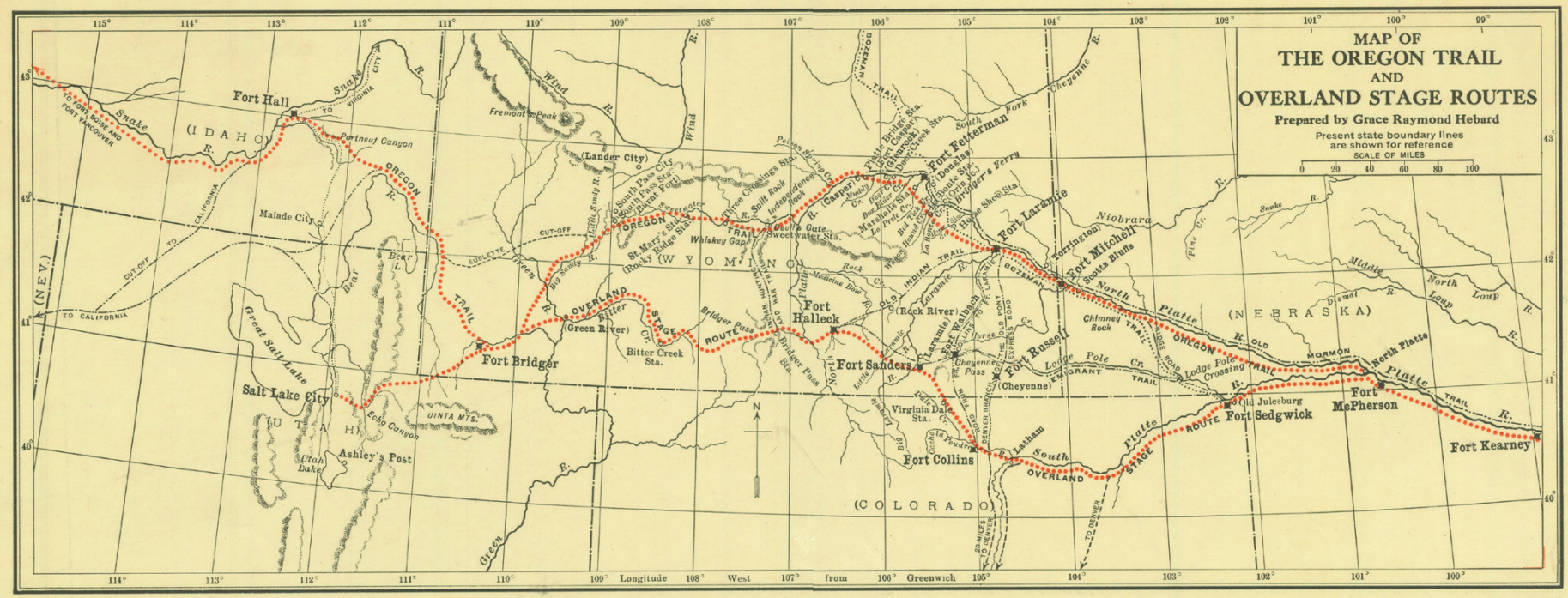

Copyright 1922, by Grace Raymond Hebard and E. A. Brininstoo

Figure 2: Map of the Oregon Trail and Overland Stage Routes. 1922. Grace Raymond Hebard and E. A. Brininstool. 


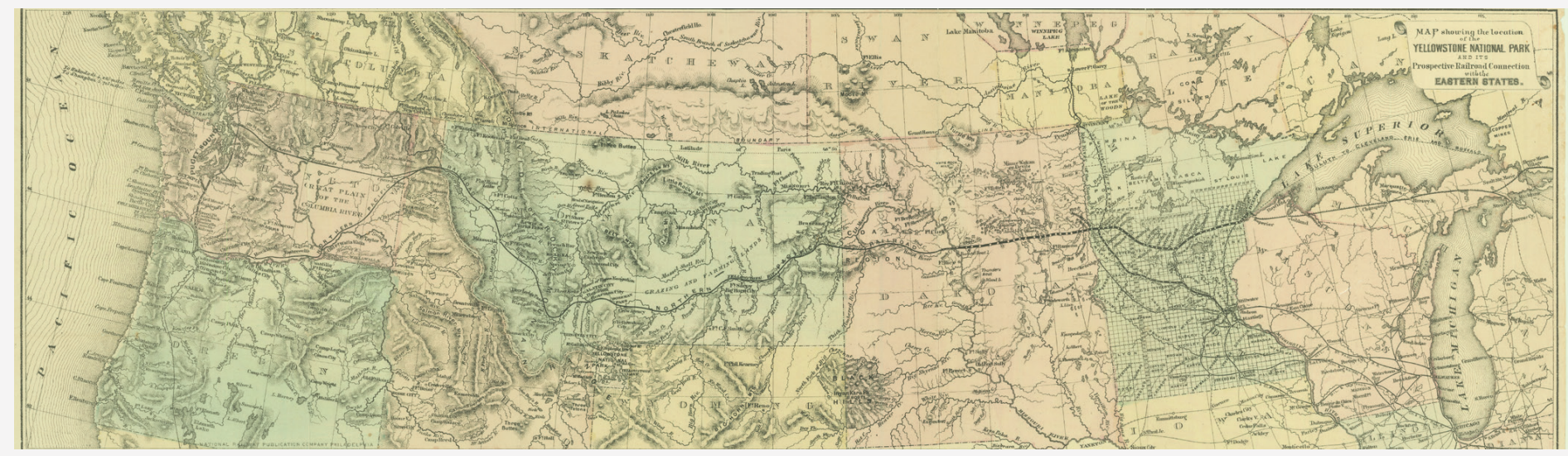

Figure 3: Map showing the location of the Yellowstone national Park and its prospective railroad connection with the Eastern States. 1872?

National Railway Publication Company.

\section{The Bozeman Trail: Historical Accounts of the Blazing of the} Overland Routes into the Northwest, and the Fights with Red Cloud's Warriors.

The Hebard Historic Map Collection received a significant addition when the University Libraries purchased a rare, hand-drawn plan of Fort Laramie, Wyoming. This plan was probably drawn on location during the late 1860 s. Rumors of its existence had circulated for years but no copies had surfaced until recently. The plan of Fort Laramie is an important find and a real jewel of the collection.

In line with the focus of the Chisum Special Collections, the Hebard Historic Map Collection contains an extensive collection of maps of Yellowstone National Park, Grand Teton National Park, and the greater Yellowstone area. These range from historical maps showing the park's situation soon after its establishment, to tourist maps and promotional materials, to recent maps showing its geology, geography, and attractions. Several railroads issued maps of their routes depicting Yellowstone as a major destination that they served (Figure 3). Some of these maps, like the one issued by the Northern Pacific Railway in 1898, are quite beautiful (Figure 4). Some of the maps in the collection are also unusual. Right Way Tourist Guides published a map of Yellowstone in 1925 that depicts routes to and through the park in a style reminiscent of an urban transit map (Figure 5). A Hysterical Map of Yellowstone Park and its sibling, A Hysterical Map of the Jackson Hole Country (Figure 6), show routes and landmarks captioned with good-natured humor.

Some of these maps illustrate another major collecting focus: maps of transportation routes in Wyoming and the West. As well as showing the locations of trails, railroads, auto trails and roads, and stations, transportation maps contain a wealth of other information about the period that they depict. For example, The B. F. Goodrich Company produced a national road map in 1915 (Figure 7) which shows major highways existing at the time (including the Lincoln Highway, which followed the route of

Figure 4: The Yellowstone National Park via the Northern Pacific Railway (detail). 1898. Northern Pacific Railway Company.

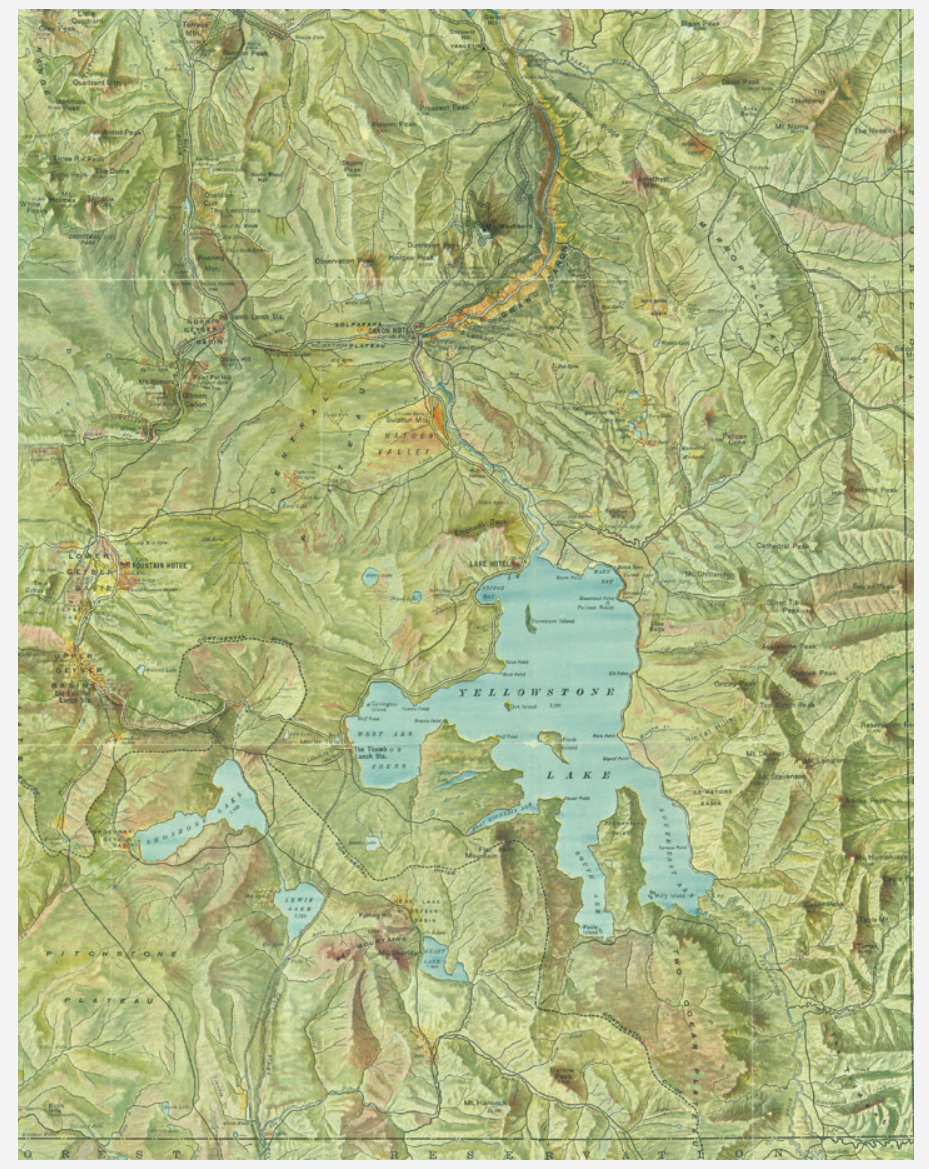



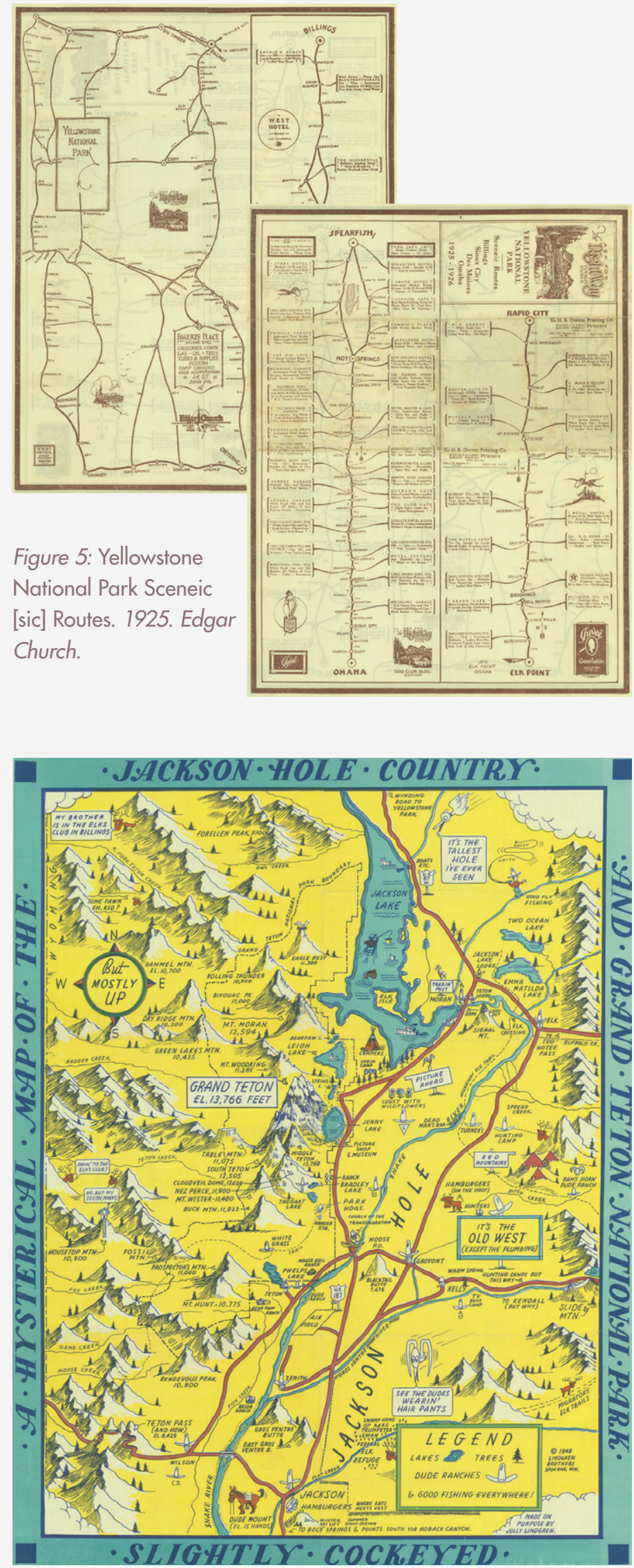

Figure 6: A Hysterical Map of the Jackson Hole Country. 1948. Jolly Lindgren.

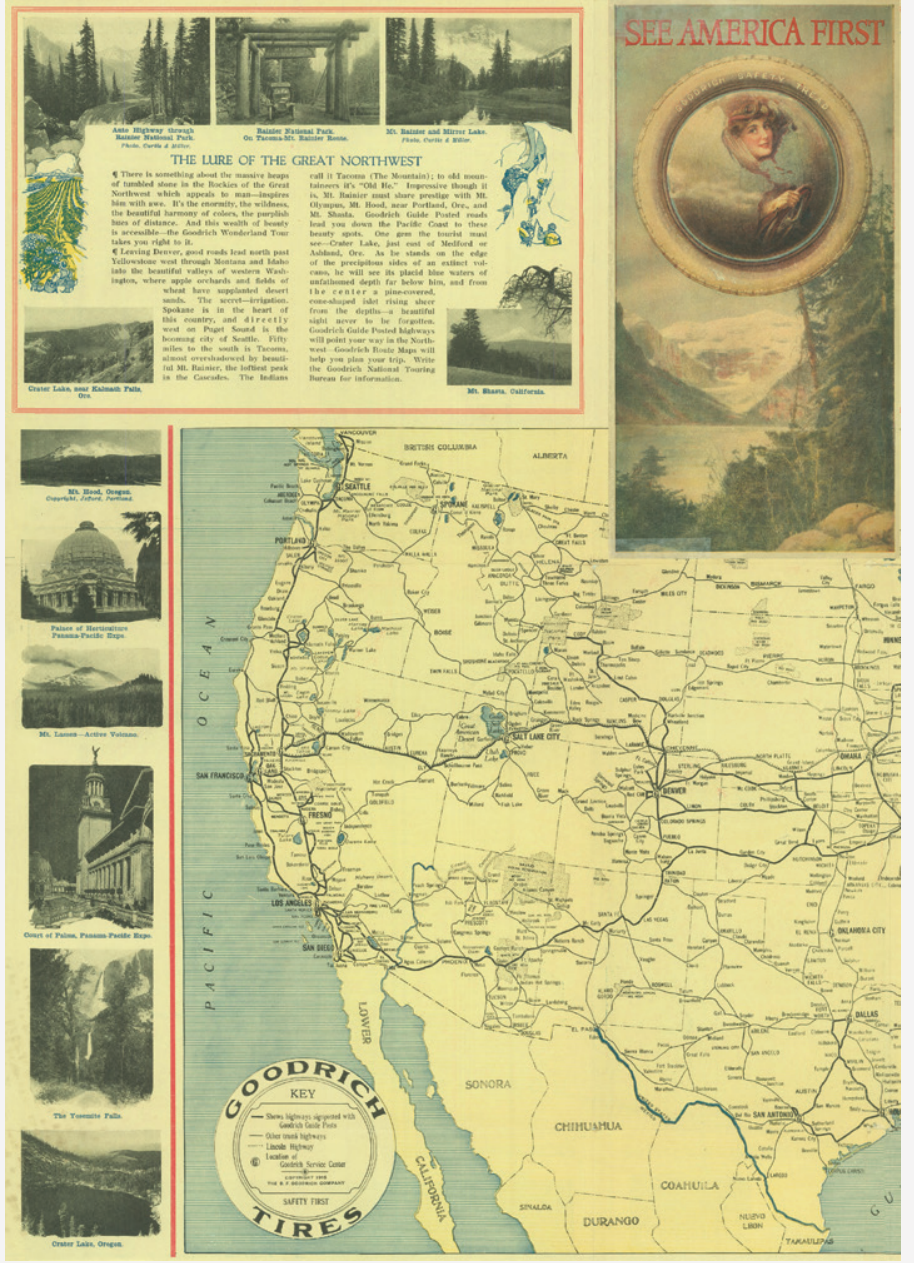

Figure 7: See America First (detail and panel). 1915. B. F. Goodrich Company.

the Transcontinental Railroad through Wyoming.) It also includes photographs of landmarks all across the country, and text lauding the excellent driving conditions in several regions (remember, they were promoting tires).

The Chisum Special Collections is actively collecting maps of other Western national parks and monuments besides Yellowstone and Grand Teton (Figure 8). The creation and development of these specially designated public lands played an important role in the history and culture of the West. Tourism in the West is another topic of interest in the collection, particularly maps and promotional materials from dude and guest ranches in the region.

Government documents of historical significance make up another important part of the collection, reflecting its origin as part of the Documents, Maps and Microforms Department (Figure 9). Important expeditions by John C. Fremont, Ferdinand V. Hayden, and others were 


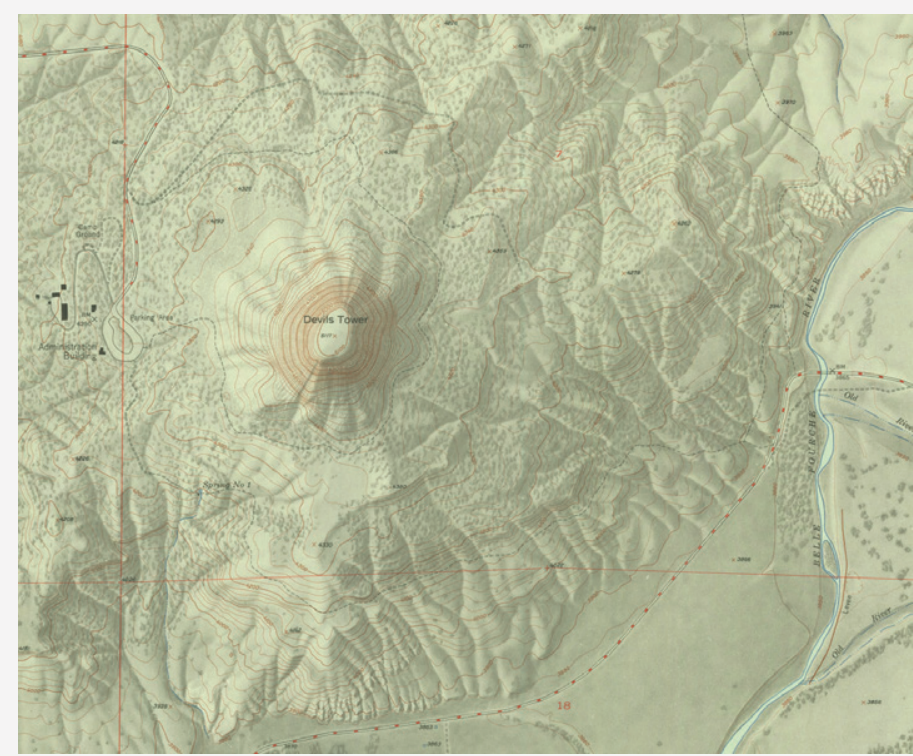

Figure 8: Devil's Tower National Monument, Wyo (detail). 1954. United States Geological Survey.

undertaken under the auspices of the federal government and the maps they produced became part of the government record (Figure 10). These maps are now a part of the Historic Map Collection. The collection also contains an extensive set of recent and historic topographic maps of Wyoming and its surrounding states.

Over the past two years, the Chisum Special Collections has made a concerted effort to digitize many of the maps

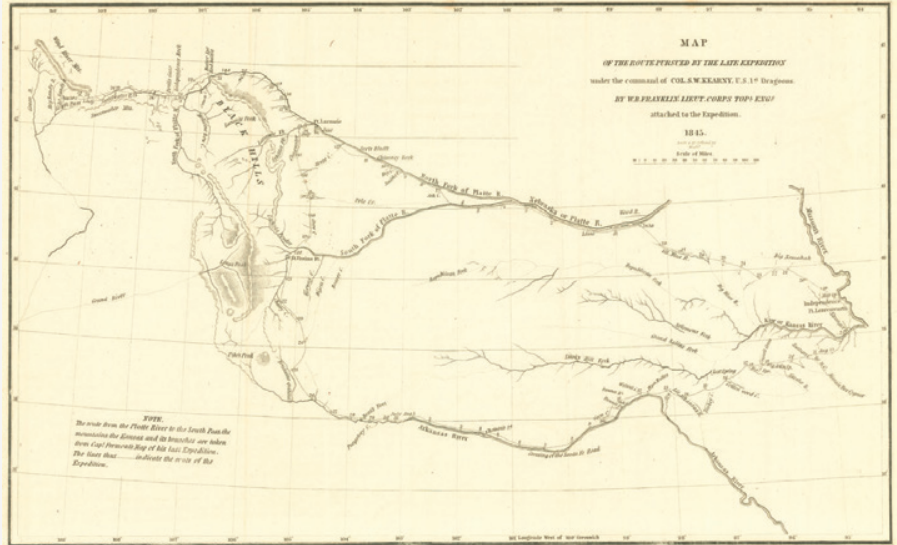

Figure 10: Map of the route pursued by the late expedition under the command of Col. S. W. Kearny, U.S. 1st Dragoons. 1845. William Buel Franklin.

in the Historic Map Collection. In partnership with the Libraries' Digital Resources Department, these maps are scanned in a large format scanner and images are added to the catalog. This provides enhanced access to the maps while minimizing wear and tear on these valuable and sometimes fragile resources.

The maps in the Hebard Historic Map Collection have been used to illustrate articles on the history of Wyoming and the West. One of the most recent of these appeared in the Summer/Autumn 2012 issue of the Annals of Wyoming: "Dr. Siegfriedt and the Black and White Trail" by Ester

Figure 9: New Map of the Route of Lewis and Clark, 1804-5-6. 1893. Elliott Coues.

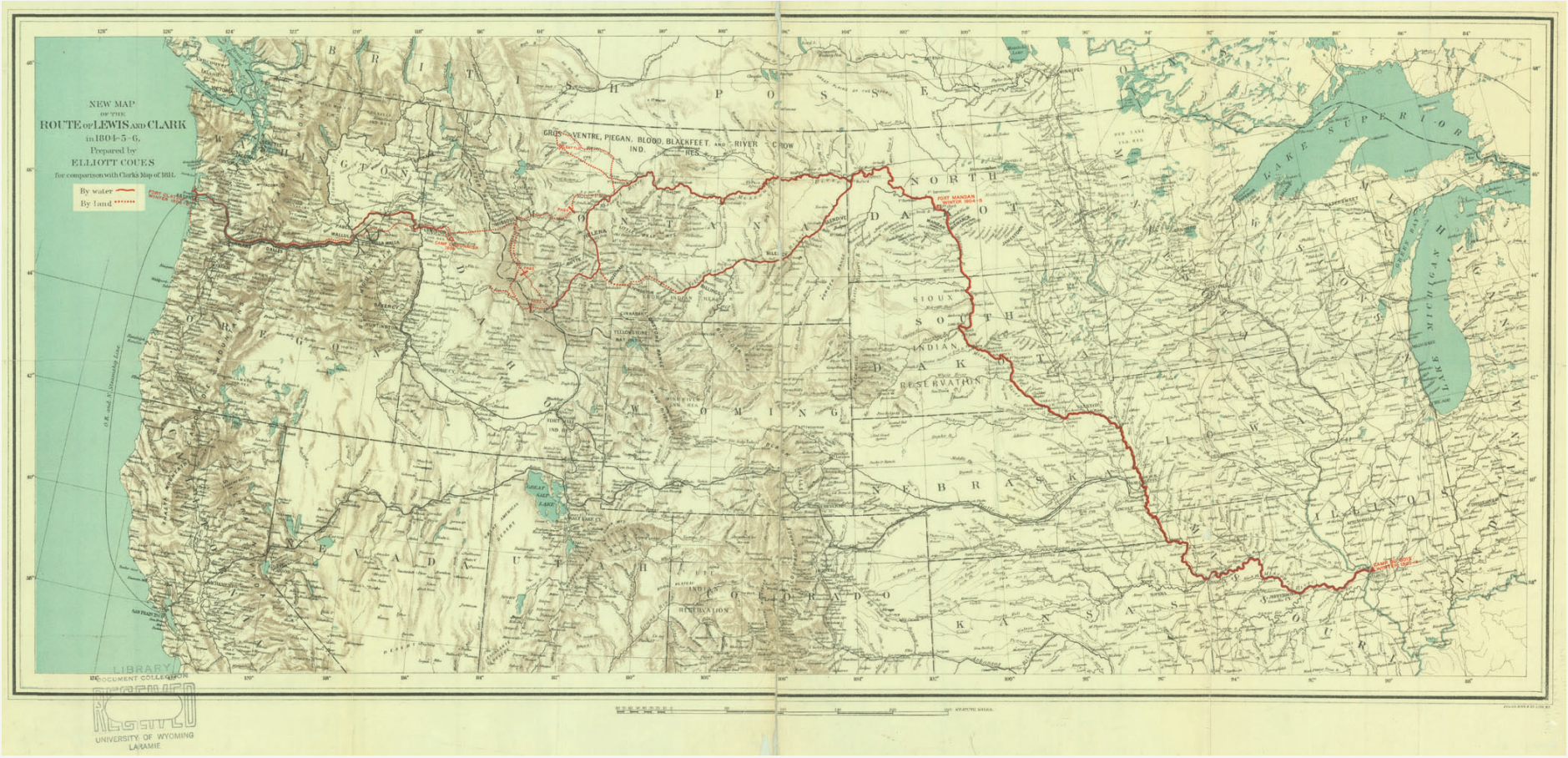


Johansson Murray. Annals editor, Rick Ewig, in collaboration with Tamsen Hert, identified maps from the Historic Map Collection to trace the development and route of the trail and to illustrate the article. The Hebard Historic Map

\section{REFERENCES}

Grace Raymond Hebard papers, 1829-1947, Collection Number 400008, American Heritage Center, University of Wyoming.

Mackey, Michael. 2005. Inventing History in the American West: the Romance and Myths of Grace Raymond Hebard. Powell, WY: Western History Publications.

Walsh, James. 1983. "Map Collection Statistics: July 1, 1982 - June 30, 1983.” Map Projections 4:3.
Collection continues to be a rich and valuable resource for researchers in the history and geography of the American West.

\footnotetext{
1984. "University Libraries Acquire 100,000th Map.” Map Projections 9:1.

1985. "Staff Changes in University of Wyoming Libraries." Map Projections 16:2.

1987. "25,000th Map Added to the Geology Library's Map Collection.” Map Projections 21-24:1.
} 
